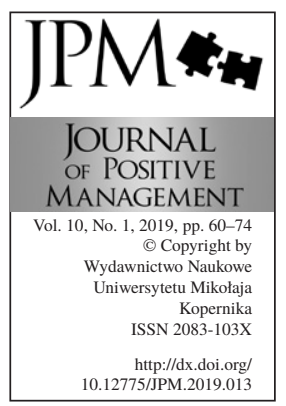

\title{
COTRANS MODEL OF KNOWLEDGE TRANSFER BASED ON THE DESIGN THINKING METHOD IN INTER-ORGANIZATIONAL RELATIONSHIPS
}

\author{
Anna Dziadkiewicz, Nelson Jorge Ribeiro Duarte ${ }^{\mathrm{b}}$, \\ Joanna Nieżurawska-Zajacc, Lech Nieżurawski ${ }^{\mathrm{d}}$ \\ ${ }^{a}$ University of Gdańsk, Faculty of Management, Gdańsk, Poland \\ ${ }^{\mathrm{b} S c h o o l}$ of Management and Technology - Polytechnic of Porto CIICESI, \\ Porto, Portugal \\ ${ }^{\mathrm{c}, \mathrm{d}}$ WSB University in Toruń, Faculty of Finance and Management, Toruń, \\ Poland \\ ae-mail: anna.dziadkiewicz@ug.edu.pl \\ be-mail: nduarte@estg.ipp.pt \\ ce-mail: joanna.niezurawska@wsb.torun.pl \\ de-mail: lech.niezurawski@wsb.torun.pl
}

\begin{abstract}
Purpose: The aim of the paper is to present a model of knowledge transfer based on a design thinking method.

Design/Methodology/approach: The structured interview method is used in the paper as well as a comparative analysis method. COTRANS model of knowledge transfer based on the design thinking method was created.
\end{abstract}

Findings: Based on the findings of the empirical study, three propositions are formulated. The first proposition is that the CONTRANS model is a good example of knowledge management. The next one shows DT method as an effective approach in creating a model of knowledge. Last one states that Scholars have argued that both academia and business are motivated to build relationships with one another.

Research limitations/implications: Authors are aware of research limitations which are caused by the methodology of convenient sample selection. The method does not guarantee a representative sample; however, it may become a premise for getting know the population.

Keywords: knowledge transfer, model of knowledge transfer, inter-organizational relationships, design thinking method

Paper type: Research Paper 


\section{Introduction}

The aim of the paper is to present a model of knowledge transfer developed during the two years of COTRANS project realization. The study was carried out as part of an international project COTRANS with project partners in Portugal and Poland (Polish - Portugal Ministerial Project "Conditionings of Knowledge Transfers and Innovative Activity of Enterprises (acronym COTRANS)" for years 2015-2017, no. 39117/2014). Three universities have participated in the project, which was undergoing since February 2015: the Faculty of Management in the University of Gdansk, the Faculty of Finance and Management in the Torun School of Banking and the School of Management and Technology of Felgueiras in the Porto Polytechnic.

Structured interview method is used in the paper as well as a comparative analysis method. The research was conducted in 2016, among 54 IT, medical and tourism enterprises from Portugal, Poland, Sweden, Denmark and Italy. As the entire study is too broad to be presented here, the authors have selected only parts of the results relevant to the subject of the paper. Additional section of the paper displays a potential model presentation with a list of recommendations on how to efficiently transfer knowledge between academia and business, which was one of the main goals of the international COTRANS project.

\section{Towards a deeper understanding of knowledge management (KM) in inter-organizational relationships}

Knowledge is a key resource that contributes to corporate renewal and competitive advantage. It is defined as the accumulated practical skill or expertise that allows one to do something smoothly and efficiently (Zander and Kogut, 1995), and knowledge transfer as transferring such knowledge between the business partners (Sarala and Vaara, 2010). Although interorganizational relations (IOR) among companies are not a recent phenomenon, they are now better developed, that is, they extend beyond a transactional level to more collaborative relationships (Malhotra et al., 2005, 2007; He et al., 2011).

Research on Knowledge Management in enterprises has been ongoing since the 1990's (Alavi, 2000; Alavi and Leidner, 2001). Schultze and Leidner (2002) propose a definition that encompasses the variety of KM initiatives: "Knowledge Management is the generation, representation, storage, transfer, transformation, application, embedding and protecting of organizational knowledge. Organizational Memory, Information Sharing and Collaborative Work are closely related concepts to Knowledge Management".

One of the most comprehensive studies in this matter was carried out by Lara Agostini and Anna Nosella (Agostini and Nosella, 2015), who reviewed the literature regarding marketing IOR's in order to develop a framework meant to organize the different contributions in this area and suggested new paths for
COTRANS MODEL OF KNOWLEDGE TRANSFER

Anna Dziadkiewicz Nelson Jorge Ribeiro Duarte Joanna Nieżurawska-Zając Lech Nieżurawski 
COTRANS MODEL OF KNOWLEDGE

TRANSFER

Anna Dziadkiewicz

Nelson Jorge Ribeiro Duarte

Joanna Nieżurawska-Zając

Lech Nieżurawski future research. A specific aspect of interorganizational knowledge management (IKM) is the capacity for two or more organizations to co-create knowledge and develop network-specific assets (Levina and Vaast, 2005; Mesquita et al., 2008). This process of co-creation underlines the importance in IKM of the network's innovation capacity. Supplier-oriented or competitor-oriented IKM projects are aimed at new ideas for products and joint new product development, while customer-oriented IKM projects focus on identifying new needs and reducing the risks of innovation and new development (Min-Antorini et al., 2012; MoyanoFuentes et al., 2012; Pittaway et al., 2004; Sobrero and Roberts, 2001). Professor Messeni Petruzeeli presented an interesting view on Knowledge Management in his article in which the authors explain the different use of organizational and cognitive proximity to acquire knowledge, according to the geographical distance between organizations. The authors believe that in order to guarantee openness and sustain innovativeness and competitiveness it seems particularly crucial to exploit all the three dimensions of proximity as regards the firm strategic behaviour (Messeni and Petruzzelli et al., 2009).

Knowledge management should be perceived as an essential component of economic growth and development of the society. The market success is determined by a skill of efficient, mostly effective, transfer of knowledge provided in the organizational procedures to economic practice. Thus, the knowledge transfer facilitates increasing the productivity and effectiveness of the operation of enterprises thanks to the assimilation of new technologies (Albino et al. 1998). In the academic context, knowledge management embraces the processes of transferring research, skills, experience and ideas within universities and from universities to a greater community of users (HMSO, 2003).

The knowledge-based approach suggests that business knowledge is one of the most strategically essential sources of competitive advantage (Spender and Grant, 1996). We can observe an increasing trend towards companies' openness for new, external knowledge to fill internal knowledge gaps and react to innovation challenges (e.g. Bojica et al., 2016). Both knowledge management and interorganisational relations (IORs) constitute an inspiration for researchers and businessmen; thus, they are the issues often described in the management literature (e.g. Meier, 2011). The topic which is frequently raised concerns the knowledge transfer (Bouncken et al., 2016). It is treated as the output of a company process, including its technological, market, and managerial nature (Burg et al., 2014). Meanwhile, inter-organisational relations can be categorized by their general types and purposes in different ways (Khamseh and Jolly, 2014; Agostini and Nosella, 2017) and they depend on the size of the company. In general, SMEs have more limited resources to build strategies than large companies. Therefore, they are forced to use their own knowledge assets to operate and compete on the market (Bojica et al., 2016). As Massaro et al. (2019) emphasized, although SMEs play 
more and more important part on the current turbulent market, little literature addresses the topic of knowledge management within and between SMEs (Massaro et al., 2019). What is more, research regarding knowledge management has not been done systematically; hence, there is lack of specific knowledge about enablers and barriers and other conditions under which the inter-organisational relations are developed (Bojica et al., 2016). As Bouncken et al. (2016) noticed, research tends to ignore the mutual knowledge creation among companies, focuses mostly on more detailed understanding of the processes, the contextual factors of joint knowledge development and intellectual assets which are necessary to create cooperation based on knowledge (Natalicchio et al., 2017).

According J.-C. Spencer (Spencer, 2006), there are some inconsistencies in $\mathrm{KM}$ literature. On the one hand, there is the belief in the increasing strategic importance of the intangibles such as knowledge. On the other, there is management's diminished ability to identify, measure, and manage them. Therefore, design thinking approach can be used to solve this weaknesses.

\section{Design thinking according to the CONTRANS Project}

The design thinking process is an increasingly important method that fosters economic growth as well as creative goals. The approach that is proposed within this paper focuses on the reflection of the enormous benefits of the concept of design thinking and its use in scientific research, that could be offered to enhance the effectiveness of modelling. Design methodologies can aid organizations which focus on the field of science and engineering. According to Achas (2010) "understanding of the role and nature of design is still woefully lacking, in comparison to the substantial work completed on defining and characterizing R\&D, science, technology and even innovation itself".

Design thinking can be a creative activity that not only solves problems, but also seeks to understand the users and challenges assumptions by redefining problems to find alternative solutions. The terms "design" such as "design thinking" are used in a wide variety of contexts with many different meanings; thus, they are difficult to define. Mainel and Leifer (2011) stressed "design thinking - its human-centric methodology integrates expertise from design, social sciences, engineering, and business. It blends an end-user focus with multidisciplinary collaboration and iterative improvement to produce innovative".

Design thinking has six main characteristics (Cerejo and Barbosa, 2012):

a) human and user centered (human-centred design, such as design thinking process is a deeply approach that relies on the ability of observed and developed ideas that are emotionally meaningful for the end-user, developing methods that emphasise user research);

b) holistic;

c) co-creative;
COTRANS MODEL OF KNOWLEDGE TRANSFER

Anna Dziadkiewicz Nelson Jorge Ribeiro Duarte Joanna Nieżurawska-Zając Lech Nieżurawski 
COTRANS MODEL OF KNOWLEDGE

TRANSFER

Anna Dziadkiewicz

Nelson Jorge Ribeiro Duarte

Joanna Nieżurawska-Zając

Lech Nieżurawski d) problem solving;

e) multidisciplinary;

f) abductive reasoning.

It is worth adding: empathy, integrated-thinking, optimism and the desire to experiment as the main design thinkers' features are valuable in the process of searching for new solutions (Dziadkiewicz, 2015), and these are the features that COTRANS needed for creating a solution for effective cooperation.

One of the main interests of design thinking is the expression towards the user and the audience. Therefore, the concept has a strong focus on user needs, involving the user in the process and placing them in the center of solving innovation problems (Lockwood, 2009). The process also has a strong foundation in a holistic perspective since it approves of a comprehensive analysis and a total understanding of the idea. Following this, design thinking is co-creative too. It is a link between the project and all the stakeholders involved in a project, focusing on the effectiveness of the process. Co-creation gathers users as a team to collaborate with stakeholders - they cooperate working to a more customer centric processes (Strickdorn and Schneider, 2012; Ambrose and Harris, 2010). Problem solving is one of the crucial characteristics of design thinking. It must be pointed out that design problems unlike hard, do not follow laws, theorems or formulas, that contrast with science and engineering disciplines. Therefore, design thinking tools can take special relevance and allow designers to position or reposition the problems at hand. For Buchanan (1992) design thinking is based on "the tools by which a designer intuitively or deliberately shapes a design situation, identifying the views of all participants, the issues which concern them and the invention that will serve as a working hypothesis for exploration and development". As a result of a great selection of methods and tools from various disciplines in order to explore and understand the behavior and mindset of all the people involved (Strickdorn and Schneider, 2012), design thinking also has a multidisciplinary characteristic. Due to the fact, that designers use abductive reasoning, they can take incomplete data, manipulate it and invent things or ideas that are relevant, innovative or appropriate - this is one of the main aspects of design thinking (Martin, 2009; Kolkom, 2011; Goldsby-Smith, 1996).

Due to the specific working style in the design thinking method and its unique approach to solve a project issue, this method has been highlighted to fix specific business issues such as the identification and classification of the factors intensifying or inhibiting knowledge and innovation transfer between enterprises and external academia sources.

According to the design thinking methodology, the objective of COTRANS was to solve not only the stated problem at hand, but the real problems behind the obvious. The most effective way to do so was to involve users, researchers, and businesspeople from different cultures and backgrounds, with different points of 
view in an integrative process, which could be applied to cooperation design and was composed of three main phases (Brown, 2009):

a) inspiration (issue identification and research),

b) ideation (idea generation)

c) implementation (prototyping, testing and market launching).

The first stage was based on empathy and deep understanding of users that was made by the main COTRANS executor in 2010 at the Laurea University of Applied Sciences in Helsinki.

This reciprocal relation takes us to the concept of knowledge exchange. Knowledge exchange presents a wider perspective for University-Industry Collaboration (UIC) as it implies a bi-directional exchange of knowledge. Under this perspective, the customer's role is no longer that of a passive recipient of value at the end of a transaction, but is that of a co-creator of value with the supplier during exchange (Canhoto et al., 2016). Scholars have argued that both university authorities and business representatives are motivated to build relationships with one another, taking advantage of their complementary organizational strengths (Mueller, 2006; Siegel et al., 2003). Usually the factors used to measure knowledge exchange do not vary from those used to analyze knowledge transfer. Under research for the COTRANS project, Duarte et al. (2016) presented a list of factors that might be used both for knowledge transfer and knowledge exchange. According to Bekkers and Freitas (2008) normally, the process starts with a firm defining its own strategy for interaction with a university and consequently, when a trust relation is built, the exchange is simpler (Plewa et al., 2013). The idea of trust is supported by issues of communication and understanding (Barnes et al., 2002; Kim, 2009).

According to the Finnish model, each company unable to manage its specific business issues, turned to a knowledge transfer coordinator for support, who subsequently appointed a project manager and together with a multidisciplinary team and students searched for an optimal solution. The main problem between knowledge transfer in Poland and Finland was students' participation in the problem-solving process (they, as project members, got ECTS points, in contrast to participation in lectures or exams). Additionally the SME's budget allocated funding for the project team. The Laurea University was a founder of knowledge management in Finland, having successfully implemented its model of knowledge transfer in Finnish businesses (Niezurawska and Śmiatacz, 2012).

The cooperation between $R \& D$ individuals and businesses was supported by dedicated data base of SME's. Summarizing, the study of the Finnish knowledge transfer model, connected with a few bilateral study tours to the School of Felgueiras, University of Gdansk, WSB University in Torun and Linnaeus University in Kalmar, associated with literature review allowed the Polish and Portuguese team elaborate on the framework of COTRANS goals at the beginning of 2015.
COTRANS MODEL OF KNOWLEDGE TRANSFER

Anna Dziadkiewicz Nelson Jorge Ribeiro Duarte Joanna Nieżurawska-Zając Lech Nieżurawski 
COTRANS MODEL OF KNOWLEDGE

TRANSFER

Anna Dziadkiewicz

Nelson Jorge Ribeiro Duarte

Joanna Nieżurawska-Zając

Lech Nieżurawski
It is worth mentioning, that issue understanding, observation and definition that create an inspiration phase have been often ignored or considered incidentally. As it appeared, a proper elaboration of fundamentals can consequently interfere with project's success. Summarizing, the study of the Finnish knowledge transfer model, connected with literature review (Dziadkiewicz and Niezurawska, 2014), (Duarte et al., 2016) allowed the Polish and Portuguese team to develop the framework of COTRANS and initiate the second phase - ideating.

This undertaking has been reflected on many possible ideas as how to create the most effective model of knowledge transfer. As a result, the questionnaire to structure interview was created as well as a comparative analysis method. The next stage involved experimenting - the research of companies that highlights the enablers and barriers, and finally - testing.

\section{Aim and process of development of CONTRANS}

The aim of the project entitled Conditionings of Knowledge Transfers and Innovative Activity of Enterprises (acronym COTRANS) is the development of a knowledge transfer model and the identification and classification of the factors intensifying or inhibiting knowledge and innovation transfer between enterprises and external sources of knowledge e.g. universities and R\&D institutions.

Primarily, three higher education institutes have participated in the project: the Faculty of Management in the University of Gdansk, the Faculty of Finance and Management at WSB University in Torun and the School of Management and Technology of Porto Polytechnic.

In order to develop the study on these concepts, a team of Portuguese and Polish researchers is cooperating with the following objectives:

- identifying enterprises' external knowledge sources;

- identifying and enumerating the factors intensifying and inhibiting knowledge and innovation transfer between universities and enterprises;

- analyzing the existing transfer models in Portugal and Poland Comparative study;

- developing a reference model for innovation and knowledge transfer.

The final goal of this paper is to present a conceptual model based on literature review, and to assess the model through field research.

Following two years of studies, initiated in Poland and Portugal, research has since come to a close. Currently there are other institutions testing the project results: Sweden (Linnaeus University in Kalmar and Växjö), Poland (University of Warmia and Mazury in Olsztyn), Italy (University of Sannio in Benevento) and business in Poland and Denmark: NGO's and SME's from the tourism, medical, and IT branch.

Based on this research, certain primary conclusions can be drawn in order to better understand the conditions for knowledge transfer, in particular from higher education institutions (directly or through their intermediaries) to industry. 
The first conclusion is related to the major role that the higher education system plays in supporting innovation under knowledge transfer activities. However, it is important to mention that the same factor can be identified as a barrier or as an enhancer; according to the context and stakeholders involved. For instance, past successful experiences among the stakeholders will decrease the costs of collaboration/cooperation.

The process of knowledge transfer usually undergoes three main steps: Exploration, Acquisition and Exploitation. Depending on the maturity of knowledge transfer of the institutions involved, each interaction may start at a different level. For a firm that is just beginning to engage in innovation activities, knowledge transfer is the recommended approach when exploring the market. However, for a firm and a knowledge producer (university) that have been working together on a new project, knowledge transfer may not be the only option. It can start immediately with the exploitation of knowledge for both parties.

The ideation stage began in April 2015. Virtual network organization and participation in domestic and international scientific conferences and workshops (in Lisbon - Portugal, Rome - Italy, Sardinia - Italy, Benevento - Italy, Kalmar - Sweden) as well as interviews with SME's and R\&D entities where parts of the work packages. This undertaking has continued over the space of a year, ending in June 2016. It has been reflected on many possible ideas as how to create the most effective model of knowledge transfer. It is worth stating, that ideation is a critical element of design thinking. All participants were challenged to brainstorm ideas and to suspend judgements. Each team was asked to generate one hundred options in a single session both in Portugal and Poland (Dryl et al., 2015). As a result, the questionnaire of the structure interview was created. Then 18 IT enterprises from Sweden, Poland and Portugal were asked about enablers and barriers of knowledge transfer (Niezurawska et al., 2016). In the same year, an additional 18 medical enterprises from Poland, Denmark and Portugal, as well as 18 tourism companies (from Poland, Sweden and Italy) were asked about the same issues.

\section{Methodology of research}

The structured interview method is used in this paper as well as a comparative analysis method. The research was conducted in 2016, among 54 IT, medical and tourism enterprises from Portugal, Poland, Sweden, Denmark and Italy. The additional section of the paper is a potential model presentation with a list of recommendations of how to make the knowledge transfer between academia and business effective, being one of the main goals of an international project COTRANS. The model of knowledge transfer assumed business diversity, thus IT, medical and tourist branches were selected. The respondents were asked to prioritize certain barriers and enablers of knowledge transfer following the rule:
COTRANS MODEL OF KNOWLEDGE TRANSFER

Anna Dziadkiewicz Nelson Jorge Ribeiro Duarte Joanna Nieżurawska-Zając Lech Nieżurawski 
COTRANS MODEL OF KNOWLEDGE

TRANSFER

Anna Dziadkiewicz

Nelson Jorge Ribeiro Duarte

Joanna Nieżurawska-Zając

Lech Nieżurawski
- -2 - significant barrier,

- -1 - barrier,

- 0 - unimportant factor,

- 1 - important but not crucial factor,

- 2 - a crucial factor.

In order to hierarchize them, an importance index was used.

\section{Summary of results}

The companies of this study were micro, small and medium businesses from Sweden (SWE), Poland (POL), Portugal (PRT), Denmark (DEK) and Italy (ITA). The majority of them have shown to believe that cooperation between enterprise and $\mathrm{R} \& \mathrm{D}$ units and institutions from the business environment is important, but not crucial (POL - 50\%, PRT $-83.33 \%$, ITA - 67\%). Only Sweden and Denmark agreed the factor to be vital (100\%). Moreover, all of the businesses cooperate with $\mathrm{R} \& \mathrm{D}$ institutions and/or business angel associations, but this cooperation is mostly occasional (POL, ITA, PRT) and frequent only in Sweden and Denmark.

The respondents were asked to prioritize the selected stimulants of knowledge transfer. Grants from the EU play a key role in each of the countries. The respondents also stated, that ministerial grants are significant in enabling knowledge transfer. Nonetheless, in Portugal and Italy there is no ministerial financial support. The similarities boil down to the fact that the most important factors of knowledge transfer are: knowledge of entrepreneurs considering cooperation, level of trust of this kind of cooperation and efficient communication between entrepreneurs and R\&D units. Access to Technological Centers/Parks was considered as the least important.

The respondents were also asked to prioritize the selected barriers of knowledge transfer. This identification seemed to be crucial in eliminating dysfunctions. By identifying the main barriers it might be possible to improve the knowledge transfer process, and to develop its effectiveness.

According to our research crucial factors which determine the knowledge transfer are financial resources/grants, knowledge of companies and businessmen considering collaboration, as well as law/regulation. In Poland, Italy and Portugal, bureaucracy has shown to hamper cooperation between universities and businesses. It means, that connections between the academia and business are particularly difficult and require bilateral open cooperation.

Administration and management attitudes regarding cooperation constitutes the largest barrier in Poland, although in Sweden, Denmark, Italy and Portugal it is of lesser significance. Formal and law regulation do not constitute a visible barrier for Portuguese entrepreneurs, likewise in Scandinavia and Italy, whereas in Poland it is a significant barrier. 
It is not possible to halt knowledge transfer, however many changes discussed in this paper, should be introduced both in Poland, Italy, and Portugal, especially legal regulations aiding collaboration. The differences among IT, medical and tourism sectors are slight and mainly refer to the EU funding accessibility.

\section{COTRANS model of knowledge transfer based on the design thinking method as the example of knowledge management in inter-organizational relationships}

As previously presented the knowledge transfer may also refer to knowledge exchange, thus during this study it was also possible to identify two sides of transfer: academia and business environment with a two-way process (to and from academia and business). This effect was due to the fact that each side is both a knowledge owner and taker. Students, graduates and lecturers/researchers are representatives of universities, with the latter also being a "knowledge source" in the transfer/exchange process.

University authorities cannot be forgotten as a factor, which initiate joint cooperation of these two environments. Summarizing, academia consists of students and graduates, lecturers/researchers, university administration and authorities, whereas entrepreneurs with their employees and business practitioners constitute the business side. The main reason for cooperation is a two-way need for knowledge, that signalizes an education gap, both from academia (that provide theoretical background, reports, analysis, surveys etc.) and business (that provide practical experience, skills and competences). This dual approach is composed of three main factors: knowledge (K), skills (S) and experience (E). What must be emphasized is that all common activities are impossible without a strong network, in the form of Technology Transfer Centers (or other organizations such as partner's club, scientific leagues or creative lounges, that are a tool for building effective relationships (see Figure 1), in which the independent knowledge center plays the indisputable role.

The next stage, based on the design thinking method includes implementation, consisting of two parts: prototyping and testing. Prototypes can take the form of concept sketches, physical mock-ups, stories, role playing and story boards -any visualization of the concept which communicates the ideas to the team. In the COTRANS project, the prototype is a model of knowledge transfer elaborated during two years of project duration. In practice, these kind of relations are not popular, thus the universities usually boot business cooperation without consultation with entrepreneurs. In the suggested model, businesses should be more involved in research activities. Another suggestion is for the independence of these centers in cooperation. By being autonomous these centers can be more effective. A total disjunction of university employee duties (both administrative and research) makes up the next significant change. The model provides for substantive support of business practitioners in creation of cooperation centers.
COTRANS MODEL OF KNOWLEDGE TRANSFER

Anna Dziadkiewicz Nelson Jorge Ribeiro Duarte Joanna Nieżurawska-Zając Lech Nieżurawski 
COTRANS MODEL

OF KNOWLEDGE

TRANSFER

Anna Dziadkiewicz

Nelson Jorge Ribeiro Duarte Joanna Nieżurawska-Zając Lech Nieżurawski

Figure 1.

COTRANS model of knowledge transfer

Source: results of own research (see also in: Duarte et al., 2017).

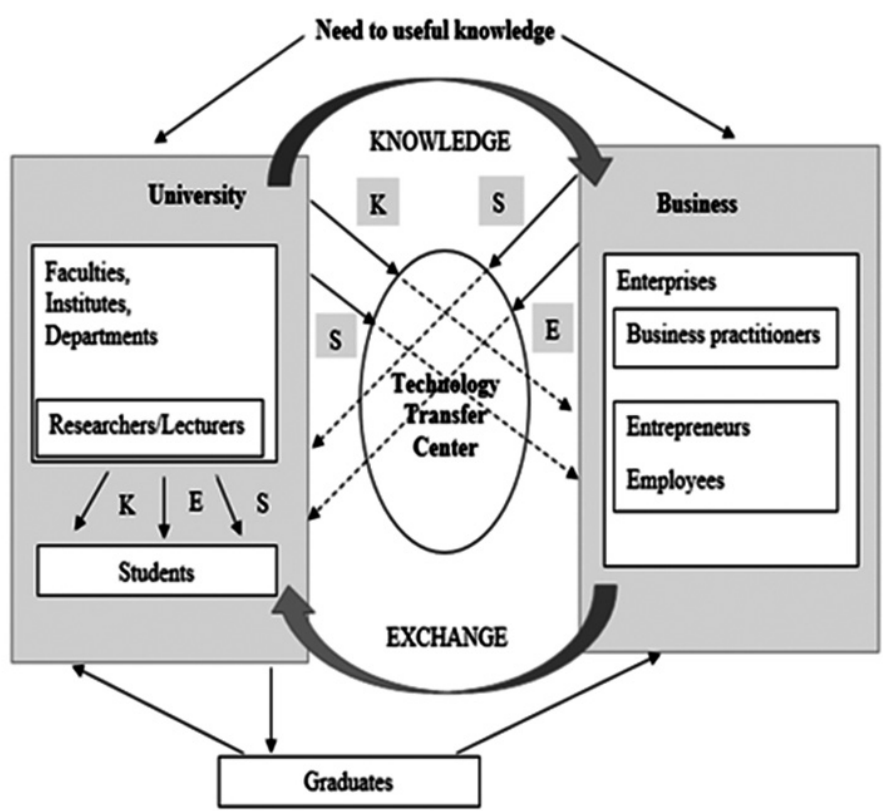

8. Conclusion

The transfer between knowledge seekers and takers can be used when organizing the academia-business cooperation. The knowledge center employees have influence on the process management, aiming to combine both sides' expectations. It is possible due to assessment of the need of knowledge. The form of knowledge transfer is also monitored and fit: workshops and courses/classes are used mainly for transfer of theoretical knowledge, in contrast to skills and experience that are transferred via work shadowing and traineeship. Starting the project, entitled "Conditionings of Knowledge Transfers and Innovative Activity of Enterprises" researchers assumed a model of knowledge transfer as the final added value. Meanwhile it turned out, that there are many more possibilities that can be created and developed within the scientific cooperation. Beneficiaries during the testing at the University of Gdansk and Felgueiras have positively assessed the model in transferring both the best practices and useful state of knowledge. The conclusion is that, COTRANS model of knowledge transfer which shows inter-organizational relationships is dynamic and has the ability to evaluate. The authors of the model believe it can be a cause for further studies.

\section{Implication}

Modernization of higher education in the context of socio-economic development is one of the priorities of the European Union's educational policy - Lisbon 
self-reforming universities in the EU have to include the implementation of goals established by the aforementioned strategies.

However, the cooperation between enterprises and R\&D units and institutions is not of equal importance in all of the countries. In Sweden, the cooperation between enterprises and R\&D units and institutions from the business environment is an important factor. In Poland and in Portugal, the cooperation between enterprises and R\&D units and institutions from the business environment is not crucial. It may be safely assumed, that under the European Support Framework Europe 2020 - the knowledge transfer will play a more and more important role in Sweden, Poland, Portugal, as well as all other EU member states. which in turn translates to low level of cooperation between university and the economy, as it is extremely hard for the academia to respond quickly to changes in the labor market or the needs reported by employers. It is worth saying, that practical implications were based on two-year observation. The results (the COTRANS model) were conducted during design thinking sessions in all presented countries in which the selected model solutions were prototyped and then tested.

Findings are the following:

1) CONTRANS model of knowledge transfer as a good example of knowledge management in inter-organizational relationships.

2) Design thinking method as an effective tool/approach/ used to create the model of knowledge transfer in inter-organizational relationships.

3) Scholars have argued that both university authorities and business representatives are motivated to build relationships with one another.

4) Universities tend to intensify the attempts of collaboration between the scientific and the economic world (these actions can be seen clearly in Scandinavian countries).

5) In Poland and Portugal, the range of activities of universities' research units partnering with businesses depends on the school's authorities. Activities undertaken by the academia are often characterized by little flexibility and small adjustability to the market needs.

6) Crucial factors which determine the knowledge transfer are financial resources/grants, knowledge of companies and businessmen considering collaboration, as well as law/regulation.

During the research followed by observation of inter-organizational relationships, we could notice the new area for further research. Since our model is constantly evolving, it is necessary to carry out the new research, taking into consideration the new procedures and assumptions of the new higher education reform in Poland, implemented in 2019.

Summarizing, it is worth saying, that knowledge transfer is inevitable. However, for it to proceed smoothly, knowledge of entrepreneurs considering cooperation should be increased, and tools merging the cooperation should be
COTRANS MODEL OF KNOWLEDGE TRANSFER

Anna Dziadkiewicz Nelson Jorge Ribeiro Duarte Joanna Nieżurawska-Zając Lech Nieżurawski 
COTRANS MODEL OF KNOWLEDGE

TRANSFER

Anna Dziadkiewicz Nelson Jorge Ribeiro Duarte Joanna Nieżurawska-Zając Lech Nieżurawski created, such as information points, where qualified staff would help in creating an effective collaboration and would assist in communication between entrepreneurs and R\&D units. Additional changes are needed in the country's legal systems. The state should support knowledge transfer not only financially, but also by creating an appropriate legal system. These changes are needed especially in Poland and Portugal.

\section{References}

Acha, V.L. (2010), “Open by Design: The Role of Design in Open Innovation”, Working paper, DIUS Research Report, Tanaka Business School, Imperial College London, Department for Innovation, Universities \& Skills, London, 8 October.

Agostini, L., Nosella, A. (2015), "Inter-Organizational Relationships in Marketing: A Critical Review and Research Agenda", International Journal of Management Reviews, Vol. 19 No. 2, pp. 131-150.

Alavi, M. (2000), "Managing organizational knowledge", in: Zmud, R.W. (Ed.), Framing the domains of IT management: Projecting the future... from the past, Pinnaflex Educational Resources, Cincinnati, Ohio, pp. 15-28.

Alavi, M., Leidner, D. (2001), "Knowledge Management and Knowledge Management Systems: Conceptual Foundations and Research Issues", Management Information Systems Quarterly, Vol. 25 No. 1, pp. 107-136.

Albino, V., Garavelli, C.A., Schiuma, G. (1998), "Knowledge transfer and inter-firm relationships in industrial districts: the role of the leader firm", Technovation, Vol. 19 No. 1, pp. 53-63.

Ambrose, G., Harris, P. (2010), Design Thinking, Basic Design Series No. 08, AVA Publishing's Academia, Singapore.

Bojica, A.M., Estrada, I., Fuentes Fuentes, M.M. (2016), "In Good Company: When Small and Medium Sized Enterprises Acquire Multiplex Knowledge from Key Commercial Partners”, Journal of Small Business Management, Vol. 56 No. 2, pp. 294-311.

Bouncken, R.B., Pesch, R., Reuschl, A.J. (2016), “Copoiesis: Mutual knowledge creation in alliances", Journal of Innovation \& Knowledge, Vol. 1 No. 1, pp. 44-50.

Buchanan, R. (1992), "Wicked Problems in Design Thinking”, Design Issues, Vol. 8 No. 2, pp. 5-21.

Burg, E. van, Berends, H., Raaij, E. van (2014), "Framing and interorganizational knowledge transfer: A process study of collaborative innovation in the aircraft industry", Journal of Management Studies, Vol. 51 No. 3, pp. 349-378.

Cerejo, J., Barbosa, A. (2012), "The application of design thinking methodology on research practices: a mind-map of tools and method", in: Media on Design Thinking in Education, Media, and Society, proceedings of the $62^{\text {nd }}$ Annual Conference of the International Council for Education in Nicosia, Cyprus, 26-29, September 2012.

Dryl, W., Dryl, T., Duarte, N.J.R., Dziadkiewicz, A., Nieżurawska, J., Nieżurawski, L., Lopes, T.F.F., Pereira, C.S.G., Vitor, S.R. (2015), “Knowledge Transfer in Network Organization. An example of the Polish-Portuguese Network of Researchers (preliminary phase)", Torun Business Review, Vol. 14 No. 1, pp. 37-46. 
Lopes, T.F.F., Pereira, C.S.G., Vitor, S.R. (2017), "Knowledge Transfer In Poland And Portugal (CLOSING Phase) - Summary Of Cotrans Project", Torun Business Review, Vol. 16 No. 1, pp. 49-61.

He, Q., Gallear, D., Ghobadian, A. (2011), "Knowledge Transfer: The Facilitating Attributes in Supply-Chain Partnerships", Information Systems Management, Vol. 28 No. 1, pp. 57-70.

HMSO (2003), Lambert Review of Business-University Collaboration: Final Report, HMSO, London.

Khamseh, H.M., Jolly, D. (2014), "Knowledge transfer in alliances: the moderating role of the alliance type", Knowledge Management Research \& Practice, Vol. 12 No. 4, pp. 409-420.

Kolko, J. (2011), Exposing the Magic of Design, A Practitioner's Guide to the Methods and Theory of Synthesis, Oxford University Press Inc., New York.

Levina, N., Vaast, E. (2005), "The emergence of boundary spanning competence in practice: implications for implementation and use of information systems", Management Information Systems Quarterly, Vol. 29 No. 2, pp. 335-363.

Lockwood, T. (2009), “Transition: How to Become a More Design-Minded Organization”, Design Management Review, Vol. 20 No. 3, pp. 27-37.

Malhotra, A., Gosain, S., El Sawy, O.A. (2005), "Absorptive capacity configurations in supply chains: gearing for partner-enabled mark and knowledge creation", Management Information Systems Quarterly, Vol. 29 No. 1, pp. 145-187.

Malhotra, A., Gosain, S., El Sawy, O.A. (2007), "Leveraging Standard Electronic Business Interfaces to enable Adaptive Supply Chain Partnerships", Information Systems Research, Vol. 18 No. 3, pp. 260-279.

Martin, R. (2009), The Design of Business. Why Design Thinking is the next competitive advantage, Harvard Business Press, Boston.

Massaro, M., Moro, A., Aschauer, E., Fink, M. (2019), “Trust, control and knowledge transfer in small business networks", Review of Managerial Science, Vol. 13 No. 2 , pp. 267-301.

Meier, M. (2011), "Knowledge management in strategic alliances: a review of empirical evidence”, International Journal of Management Reviews, Vol. 13 No. 1, pp. 1-23.

Mesquita, L.F., Anand, J., Brush, T.H. (2008), "Comparing the resource-based and relational views: knowledge transfer and spillover in vertical alliances", Strategic Management Journal, Vol. 29 No. 9, pp. 913-941.

Messeni Petruzzelli, A., Albino, V., Carbonara, N. (2009), "External knowledge sources and proximity", Journal of Knowledge Management, Vol. 13 No. 5, pp. 301-318.

Min-Antorini, Y., Muniz, A.M., Askildsen, T. (2012), "Collaborating With Customer Communities: Lessons From the Lego Group", MIT Sloan Management Review, Vol. 53 No. 3, pp. 73-79.

Moyano-Fuentes, J., Sacristán-Díaz, M., Martínez-Jurado, P.J. (2012), “Cooperation in the supply chain and lean production adoption. Evidence from the Spanish automotive industry", International Journal of Operations and Production Management, Vol. 32 No. 9, pp. 1075-1096.

Natalicchio, A., Ardito, L., Savino, T., Albino, V. (2017), “Managing knowledge assets for
COTRANS MODEL OF KNOWLEDGE TRANSFER

Anna Dziadkiewicz Nelson Jorge Ribeiro Duarte Joanna Nieżurawska-Zając Lech Nieżurawski 
COTRANS MODEL OF KNOWLEDGE

TRANSFER

Anna Dziadkiewicz

Nelson Jorge Ribeiro Duarte

Joanna Nieżurawska-Zając

Lech Nieżurawski open innovation: A systematic literature review", Journal of Knowledge Management, Vol. 21 No. 6, pp. 1362-1383.

Pittaway, L., Robertson, M., Munir, K., Denyer, D., Neely, A. (2004), "Networking and innovation: a systematic review of evidence", International Journal of Management Reviews, Vol. 5/6 No. 3-4, pp. 137-168.

Sarala, R., Vaara, E. (2010), "Cultural differences, cultural convergence and crossvergence as explanations of knowledge transfer in international acquisitions", Journal of International Business Studies, Vol. 41 No. 8, pp. 1365-1390.

Schultze, U., Leidner, D.E. (2002), "Studying Knowledge Management in Information Systems Research: discourses and theoretical assumptions", Management Information Systems Quarterly, Vol. 26 No. 3, pp. 213-242.

Sobrero, M., Roberts, E.B. (2001), "The trade-off between efficiency and learning in interorganizational relationships for product development", Management Science, Vol. 47 No. 4, pp. 493-511.

Spender, J.-Ch. (2006), “Getting value from knowledge management", The TQM Magazine, Vol. 18 No. 3, pp. 238-254.

Spender, J.-Ch., Grant, R.M. (1996), "Knowledge and the Firm: Overview, Strategic Management Journal, Vol. 17 No. S2, pp. 5-9.

Zander, U., Kogut, B. (1995), "Knowledge and the speed of the transfer and imitation of organizational capabilities: An empirical test", Organization Science, Vol. 6 No. 1, pp. 76-92. 